\title{
Faktor-faktor yang mempengaruhi tunggakan pajak kendaraan bermotor Kabupaten Tanjung Jabung Barat (studi kasus: Kecamatan Tungkal Ilir)
}

\author{
Eymilia Oktavia*; Muhammad Safri; Yohanes Vyn Amzar
}

Prodi Ekonomi Pembangunan, Fak. Ekonomi dan Bisnis, Universitas Jambi

*E-mail korespondensi : eymiliaoktavia20@gmail.com

\begin{abstract}
This study aims to identify and analyze: 1) the characteristics of PKB arrears in terms of age, education level, income, and the motor vehicle tax service system (PKB) in Tungkal Ilir District and 2). The influence of age, education level, income, and the motor vehicle tax service system (PKB) on motor vehicle tax arrears in Tungkal Ilir District. The data analysis method used in this study used a descriptive and regression analysis model. Based on the results of the study, it was obtained: The characteristics of the respondents in this case the individual motorized vehicle taxpayers (PKB) in Tungkal Ilir District were: the average age of the respondents in this study was 33 years, the average education level of the respondents is high school/equivalent and the average monthly income/income is $R p$. 2,486,000. Age (U) has a positive and significant effect on arrears of Motor Vehicle Taxes, while the level of education (TP), income $(P)$, and the tax service system (SP) has a negative and significant effect on arrears of Motor Vehicle Taxes in Tungkal Ilir District, both together -equally or partially.
\end{abstract}

Keywords: Tax arrears, Motor vehicles, Multiple regression analysis

\begin{abstract}
Abstrak
Penelitian ini bertujuan untuk mengetahui dan menganalisis: 1). Karakteristik penunggak PKB dilihat dari aspek umur, tingkat pendidikan, pendapatan, dan sistem pelayanan pajak kendaraan bermotor (PKB) di Kecamatan Tungkal Ilir dan 2). Pengaruh pengaruh umur, tingkat pendidikan, pendapatan, dan sistem pelayanan pajak kendaraan bermotor (PKB) terhadap tunggakan pajak kendaraan bermotor di Kecamatan Tungkal Ilir. Metode analisis data yang digunakan dalam penelitian ini menggunakan analisis deskriptif dan modelanalisis regresi.Berdasarkan hasil penelitian diperoleh : Karakteristik responden dalam hal ini wajib pajak kendaraan bermotor (PKB) orang pribadi di Kecamatan Tungkal Ilir adalah: rata-rata umur responden dalam penelitian ini adalah 33 tahun, rata-rata tingkat pendidikan responden adalah jenjang SMA/sederajat dan rata-rata pendapatan/penghasilan perbulan sebesar $\mathrm{Rp}$ 2.486.000. Umur (U) berpengaruh positif dan signifikan terhadap tunggakan Pajak Kendaraan Bermotor, sedangkan tingkat pendidikan (TP), pendapatan (P), dan sistem pelayanan pajak (SP) berpengaruh negatif dan signifikan terhadap tunggakan Pajak Kendaraan Bermotor di Kecamatan Tungkal Ilir, baik secara bersama-sama maupun secara parsial.
\end{abstract}

Kata kunci : Tunggakan pajak, Kendaraan bermotor, Analisis regresi berganda

\section{PENDAHULUAN}

Tanggung jawab dalam membayar pajak sebagai warga Negara, merupakan kewajiban yang harus dilaksanakan oleh masing-masing individu. Hal ini sesuai dengan konsep self-assessment yang sekarang dijalankan dalam menghitung dan melaporkan 
pajaknya. Self-assessment merupakan suatu sistem perpajakan yang memberikan kepercayaan dan tanggung jawab kepada Wajib Pajak untuk berinisiatif mendaftarkan dirinya untuk mendapatkan NPWP (Nomor Pokok Wajib Pajak); menghitung, memperhitungkan, membayar dan melaporkan sendiri pajak terutang. Namun administrasi perpajakan saat ini dipegang oleh Direktorat Jendral Pajak, berperan aktif dalam melaksanakan pengendalian administrasi pemungutan pajak yang meliputi tugastugas pembinaan, penelitian, pengawasan, dan penerapan sanksi administrasi (UndangUndang Nomor 6 Tahun 1983).

Peranan pajak dalam pembangunan diupayakan untuk semakin meningkat dari tahun ke tahun, hal ini sejalan dengan upaya pemerintahan untuk membangun kemandirian dalam pembangunan, namun demikian, upaya tersebut masih menemui hambatan karena masih kurangnya pemahaman Wajib Pajak mengenai seluk beluk perpajakan.

Supaya penerimaan pajak itu dapat berhasil dan dapat dijadikan sumber pemasukan negara setiap Wajib Pajak mau membayar pajak, maka setiap orang harus mengerti tentang arti dan fungsi pajak itu sendiri. Tanpa adanya pengertian dari masyarakat mustahil akan terjadi peningkatan pendapatan daerah dari sektor pajak. Salah satu contohnya Wajib Pajak dalam membayar Pajak Kendaraan Bermotor (PKB).

Pajak Kendaraan Bermotor (PKB) merupakan salah satu sektor unggulan dalam kontribusinya untuk meningkatkan Pendapatan Asli Daerah. Sehingga sektor pajak dapat dikatakan sebagai gerbong dalam meningkatkan lajunya perekonomian suatu daerah.Tunggakan pajak daerah yang terjadi diakibatkan kurangnya pemahaman mengenai pajak. Kondisi ini berhubungan dengan tingkat pendidikan formal, tidak tersedianya biaya untuk pembayaran pajak yang berhubungan dengan pendapatan perbulan wajib pajak, dan kurangnya kesadaran wajib pajak dalam membayar pajak kendaran bermotor. Wajib pajak memiliki umur yang berbeda-beda serta memiliki tingkat pendidikan yang berbeda-beda.

Tabel 1. Jumlah tunggakan pajak kendaraan bermotor Tahun 2019 di Kabupaten Tanjung Jabung Barat

\begin{tabular}{lcc}
\hline Kecamatan & Jumlah kendaraan & Jumlah tunggakan (Rp) \\
\hline Tungkal Ulu & 1.296 & 824.020 .600 \\
Merlung & 1.317 & 838.247 .500 \\
Batang Asam & 2.800 & 1.256 .907 .400 \\
Tebing Tinggi & 1.795 & 998.248 .400 \\
Renah Mendaluh & 639 & 344.037 .500 \\
Muara Papalik & 798 & 490.403 .700 \\
Pengabuan & 835 & 380.794 .800 \\
Senyerang & 613 & 243.981 .400 \\
Tungkal Ilir & 5.185 & 2.207 .066 .100 \\
Bram Itam & 609 & 247.589 .000 \\
Seberang Kota & 229 & 127.138 .200 \\
Betara & 1.293 & 548.474 .300 \\
Kuala Betara & 279 & 91.396 .400 \\
\hline \multicolumn{1}{c}{ Jumlah total } & $\mathbf{1 7 . 6 8 8}$ & $\mathbf{8 . 5 9 8 . 3 0 5 . 3 0 0}$ \\
\hline
\end{tabular}

Sumber: Samsat Tanjab Barat,2019(diolah)

Berdasarkan Tabel 1 tidak bisa dipungkiri jumlah kendaraan bermotor kini terus meningkat dan jumlah tunggakan semakin meningkat pula. Hal ini diketahui 
berdasarkan data pada Kantor Samsat Kabupaten Tanjung Jabung Barat, pembelian kendaraan baru rata-rata mencapai 300 obyek dalam satu bulan. Data Tunggakan Pajak Kendaraan Bermotor dari 13 Kecamatan pada tahun 2019 mencapai 8,6 miliar. Hal ini yang membuat UPTD Samsat Kabupaten Tanjung Jabung Barat harus melakukan upaya-upaya agar pajak yang tertunggak dapat segera tercairkan. Berdasarkan permasalahan diatas maka permasalahan yang akan dibahas dalam penelitian ini mengambil di Kabupaten Tanjung Jabung Barat sebagai kawasan penelitian dengan judul: Faktor-faktor Yang Mempengaruhi Tunggakan Pajak Kendaraan Bermotor (PKB) Di Kabupaten Tanjung Jabung Barat.

\section{METODE}

\section{Jenis data}

Data adalah hasil pencatatan penulis, baik yang berupa fakta ataupun angka. Data adalah segala fakta dan angka yang dapat dijadikan bahan untuk menyusun informasi, sedangkan informasi adalah hasil pengolahan data yang dipakai untuk suatu keperluan (Marzuki, 2005). Jenis data yang digunakan adalah data kuantitatif time series (runtut waktu). Dalam hal ini data kuantitatif yang diperlukan adalah jumlah nominal dan wajib pajak yang menunggak Pajak Kendaraan Bermotor (PKB) di Kecamatan Tungkal Ilir Kabupaten Tanjung Jabung Barat.

\section{Sumber data}

Adapun sumber data yang digunakan oleh penulis dalam penelitian ini yaitu: data primer adalah data yang diperoleh langsung dari sumbernya, melalui kuisioner dan wawancara pada responden wajib pajak yang menunggak pajak kendaraan bermotor di Kabupaten Tanjung Jabung Barat.Data sekunder merupakan data yang diperoleh melalui studi dokumentasi dengan mempelajari berbagai tulisan melalui buku, jurnaljurnal penelitian, majalah, dan informasi dari internet untuk mendukung penelitian ini.

\section{Populasi}

Populasi adalah wilayah generalisasi yang terdiri atas subyek atau objek yang memiliki kualitas dan karakteristik tertentu yang ditetapkan oleh peneliti untuk dipelajari dan kemudian ditarik kesimpulannya Sugiyono (2008). Populasi dalam penelitian ini adalah jumlah penduduk Kabupaten Tanjung Jabung Barat yang menunggak dalam pembayaran pajak kendaraan bermotor (PKB) pada tahun 2019 yang mencapai 17.688 orang/wajib pajak.

\section{Pengambilan sampel}

Sampel adalah bagian dari jumlah dan karakteristik yang dimiliki oleh populasi tersebut, bila populasi besar dan peneliti tidak mungkin mempelajari semua yang ada pada populasi, misanya karena keterbatasan dana, tenaga dan waktu maka peneliti dapat menggunakan sampel yang diambil dari populasi. (Sugiyono, 2005). Teknik pengambilan sampel secara random sampling (acak). Jumlah sampel yang diambil menggunakan rumus Slovin (Umar, 2004) sebagai berikut:

Keterangan:

$$
n=\frac{N}{1+N e^{2}}
$$

$$
\begin{array}{ll}
\mathrm{n} & =\text { jumlah sampel } \\
\mathrm{N} & =\text { jumlah populasi } \\
\mathrm{e}^{2} & =\text { nilai kritis (batas ketelitian) yang diinginkan }(10 \%)
\end{array}
$$


Berdasarkan rumus Slovin, maka pengambilan sampel dari jumlah kuesioner yang diedarkan adalah sebagai berikut :

$$
n=\frac{17.688}{1+17.688(0,1)^{2}}=99,44 \text { (dibulatkan menjadi } 100 \text { responden) }
$$

\section{Metode pengumpulan data}

Kuesioner adalah suatu teknik pengumpulan informasi yang memungkinkan analis mempelajari sikap-sikap, keyakinan, perilaku, dan karakteristik beberapa orang utama di dalam organisasi yang bisa terpengaruh oleh sistem yang diajukan atau oleh sistem yang sudah ada.Studi dokumentasi dilakukan dengan cara mengumpulkan dan mempelajari data-data yang diperoleh dari berbagai macam buku, jurnal, dan informasi dari internet yang berhubungan dengan penelitian.

\section{Metode analisis data}

\section{Analisis deskriptif}

Untuk menjawab tujuan pertama pada penelitian ini yaitu karakteristik penunggak Pajak Kendaraan Bermotor (PKB) di Kecamatan Tungkal Ilir menggunakan metode analisis deskriptif kuantitatif disajikan dalam bentuk data statistik dan tabulasi. Metode analisis deskriptif kuantitatif adalah mentode yang menjelaskan dan menggambarkan suatu objek penelitian dan melakukan perbandingan antara teori dengan yang benar-benar terjadi pada objek penelitian yang di sajikan dalam bentuk tabel (Sugiyono, 2010).

\section{Analisis kuantitatif}

Metode analisis kuantitatif digunakan untuk menjawab tujuan penelitian kedua yaitu pengaruh umur, tingkat pendidikan, pendapatan, dan sistem pelayanan pajak kendaraan bermotor $(\mathrm{PKB})$ terhadap tunggakan pajak kendaraan bermotor di Kabupaten Tanjung Jabung Barat menggunakan metode analisis regresi linier berganda.

$$
\mathbf{Y}_{\mathrm{i}}=\boldsymbol{\beta}_{\mathbf{0}}+\boldsymbol{\beta}_{1} \mathbf{X}_{1 \mathrm{i}}+\boldsymbol{\beta}_{2} \mathbf{X}_{2 \mathrm{i}}+\boldsymbol{\beta}_{3} \mathbf{X}_{3 \mathrm{i}}+\boldsymbol{\beta}_{4} \mathbf{X}_{4 \mathrm{i}}+\mathbf{e}_{\mathrm{i}}
$$

Selanjutnya model tersebut ditransformasikan sesuai dengan variabel yang akan diukur penelitian ini, sehingga persamaannya menjadi:

$$
\mathbf{Y}_{\mathrm{i}}=\boldsymbol{\beta}_{\mathbf{0}}+\boldsymbol{\beta}_{1} \mathrm{U}+\boldsymbol{\beta}_{2} \mathrm{TP}+\boldsymbol{\beta}_{3} \mathbf{P}+\boldsymbol{\beta}_{4} \mathrm{SP}+\mathrm{e}_{\mathrm{i}}
$$

$$
\begin{array}{ll}
\text { Keterangan: } & \\
\mathrm{Y}_{\mathrm{i}} & =\text { Tunggakan PKB } \\
\beta_{\mathrm{o}} & =\text { Konstanta/intercept } \\
\beta_{1}, \beta_{2}, \beta_{3}, \beta_{4} & =\text { Koefisien regresi } \\
\mathrm{U} & =\text { Umur (tahun) } \\
\mathrm{TP} & =\text { Tingkat pendidikan (tahun) } \\
\mathrm{P} & =\text { Pendapatan perbulan (Rupiah) } \\
\mathrm{SP} & =\text { Sistem pelayanan } \\
\mathrm{e}_{\mathrm{i}} & =\text { Standard error }
\end{array}
$$

Uji asumsi klasik pada persamaan regresi linier berganda yang digunakan dalam penelitian ini adalah dengan melakukan uji normalitas, uji linieritas, uji 
multikolinearitas, uji heteroskedasitas dan uji autokorelasi. Sedangkan pengujian hipotesis dalam penelitian ini adalah pengujian secara bersama-sama (Uji F Statistik) dan Uji secara Parsial (Uji t Statistik).

\section{HASIL DAN PEMBAHASAN}

\section{Karakteristik responden penunggak pajak kendaraan bermotor (PKB)}

Dari 100 responden penunggak PKB yang diambil sebagai sampel dalam penelitian ini Wajib Pajak Kendaraan Bermotor (PKB) orang pribadi di Kabupaten Tanjung Jabung Barat. Karakteristik responden dapat dilihat pada tabel dibawah ini:

\section{Jenis kelamin}

Dalam penelitian ini responden berjenis kelamin laki-laki dan perempuan, adapun jumlah reponden penunggak PKB berdasarkan jenis kelamin adalah sebagai berikut:

Tabel 2. Karakteriktik Penunggak PKB Berdasarkan Jenis Kelamin

\begin{tabular}{lcc}
\hline \multicolumn{1}{c}{ Jenis kelamin } & Frekuensi (Orang) & Persentase \\
\hline Laki-laki & 46 & $46 \%$ \\
Perempuan & 54 & $54 \%$ \\
\hline Jumlah & 100 & $100 \%$
\end{tabular}

Sumber: Data diolah, 2020

Berdasarkan Tabel 2 dapat diketahui bahwa jenis kelamin responden penunggak PKB didominasi oleh responden berjenis kelamin perempuan, dengan jumlah persentase sebesar 54\%, sedangkan sisanya berjenis kelamin laki-laki. Terlihat bahwa dari data tabel 2 menunjukkan bahwa responden perempuan lebih banyak dibandingkan dengan responden penunggak PKB laki-laki. Jumlah responden perempuan sebanyak 54 orang sementara responden laki-laki berjumlah 46 orang.

\section{Tingkat umur}

Dalam penelitian ini responden penunggak PKB berdasarkan tingkat umur dibagi menjadi 4 kelompok, yaitu rentang umur 20-29 tahun, 30-39 tahun, 40-49 tahun dan $>50$ tahun.

Tabel 3. Karakteriktik Penunggak PKB Berdasarkan Tingkat Umur

\begin{tabular}{|c|c|c|}
\hline Umur (tahun) & Frekuensi (orang) & Persentase \\
\hline $24-31$ & 26 & $26 \%$ \\
\hline $32-39$ & 37 & $37 \%$ \\
\hline $40-47$ & 21 & $21 \%$ \\
\hline$>47$ & 16 & $16 \%$ \\
\hline Jumlah & 100 & $100 \%$ \\
\hline
\end{tabular}

Sumber : Data diolah, 2020

Dari Tabel 3 terlihat bahwa kelompok umur 32-39 tahun mendominasi responden penunggak PKB yang diteliti dengan persentase sebesar $37 \%$ atau sebanyak 37 orang, sedangkan kelompok umur lebih dari 50 adalah kelompok responden yang terkecil yaitu sebesar $16 \%$ atau 16 orang. Sementara kelompok umur 24-31 dan 40-47 tahun berkisar antara 20 sampai 30 persen. 


\section{Tingkat pendidikan}

Responden dikelompokan ke dalam 4 kelompok pendidikan yaitu SD.SMP, SMA, dan D3/S1. Proporsi pendidikan responden penunggak PKB dapat dilihat tabel di bawah ini:

Tabel 4. Karakteriktik Penunggak PKB Berdasarkan Tingkat Pendidikan

\begin{tabular}{|c|c|c|}
\hline Tingkat pendidikan & Frekuensi (Orang) & Persentase \\
\hline SD & 2 & $2 \%$ \\
\hline SMP & 18 & $18 \%$ \\
\hline SMA & 57 & $57 \%$ \\
\hline D3/S1 & 23 & $23 \%$ \\
\hline Jumlah & 100 & $100 \%$ \\
\hline
\end{tabular}

Sumber: Data diolah, 2020

Berdasarkan Tabel 4 dapat diketahui bahwa responden penunggak PKB dalam penelitian ini lebih didominasi pada tingkat pendidikan SMA, dengan jumlah persentase sebesar 57\% atau sebanyak 57 orang, sedangkan responden terkecil berada pada tingkat pendidikan Sekolah Dasar (SD) yaitu persentase sebesar 2\% atau 2 orang. Pada tingkat pendidikan SMP menunjukkan responden sebesar $18 \%$ atau sebanyak 18 orang dan pada tingkat pendidikan D3/S1 menunjukkan persentase sebesar $23 \%$ atau 23 orang.

\section{Jenis pekerjaan}

Dalam penelitian ini responden penunggak PKB dilihat dari jenis pekerjaan yaitu PNS, Wiraswasta, Buruh dan Urusan Rumah Tangga (URT).

Tabel 5. Karakteriktik penunggak PKB berdasarkan jenis pekerjaan

\begin{tabular}{|c|c|c|}
\hline Jenis Pekerjaan & Frekuensi (Orang) & Persentase \\
\hline PNS & 19 & $19 \%$ \\
\hline Wiraswasta & 25 & $25 \%$ \\
\hline Buruh & 20 & $20 \%$ \\
\hline URT & 36 & $36 \%$ \\
\hline Jumlah & 100 & $100 \%$ \\
\hline
\end{tabular}

Sumber : Data diolah, 2020

Berdasarkan hasil Tabel 5 di atas bahwa responden penunggak PKB dalam penelitian ini lebih dominan adalah URT dengan jumlah persentase $36 \%$ atau sebanyak 36 orang, sedangkan jumlah responden terkecil berada di jenis pekerjaan PNS. Pada responden jenis pekerjaan wiraswasta dan buruh rata-rata berada di kisaran 20-25\%.

\section{Berdasarkan pendapatan}

Dalam penelitian ini responden penunggak PKB didasarkan pada rata-rata jumlah pendapatan/penghasilan perbulan.

Tabel 6. Karakteriktik penunggak PKB berdasarkan pendapatan

\begin{tabular}{lcc}
\hline \multicolumn{1}{c}{ Penghasilan/bulan (Rp) } & Frekuensi (Orang) & Persentase \\
\hline $1.000 .000-1.900 .000$ & 24 & $24 \%$ \\
$2.000 .000-2.900 .000$ & 27 & $27 \%$ \\
$3.000 .000-3.900 .000$ & 18 & $18 \%$ \\
$4.000 .000-4.900 .000$ & 17 & $17 \%$ \\
$5.000 .000-5.900 .000$ & 11 & $11 \%$ \\
$>6.000 .000$ & 3 & $3 \%$ \\
\hline
\end{tabular}




\begin{tabular}{ccc}
\hline Jumlah & 100 & $100 \%$ \\
\hline
\end{tabular}

Sumber : Data diolah, 2020

Berdasarkan Tabel 6 dapat diketahui bahwa respondenpenunggak PKB yang memiliki penghasilan antara 2.000.000-2.900.000 adalah responden terbanyak yaitu sebesar $27 \%$ atau 27 orang, sedangkan responden terkecil berada di penghasilan di atas 6.000 .000 yaitu sebanyak 3\% atau berjumlah 3 orang. Hal ini menunjukkan bahwa masih banyak responden berpenghasilan rendah dengan rentang rata-rata 1.000.0002.900.000 per bulan.

\section{Persamaan regresi linier berganda}

Analisis data dan pengujian hipotesis dalam penelitian ini dilakukan dengan menggunakan model regresi linear berganda. Analisis regresi linier berganda ditujukan untuk menentukan hubungan linier antara beberapa variabel bebas yang terdiri dari umur (U), tingkat pendidikan (TP), pendapatan (P), sistem pelayanan pajak (SP) dan variabel terikat yaitu Tunggakan PKB (Y). Untuk mengetahui bagaimana pengaruh antar variabel bebas terhadap variabel tidak bebas tersebut dilakukan dengan menggunakan persamaan regresi linear berganda sebagai berikut :

$\mathrm{Y}_{\mathrm{i}}=\beta_{\mathrm{o}}+\beta_{1} \mathrm{U}+\beta_{2} \mathrm{TP}+\beta_{3} \mathrm{P}+\beta_{4} \mathrm{SP}+\mathrm{e}_{\mathrm{i}}$

Analisis regresi linear berganda dalam penelitian ini dapat dilihat pada Tabel di bawahanalisis Regresi Linear Berganda sebagai berikut:

Tabel 7. Hasil regresi linier berganda

\begin{tabular}{lllll}
\hline Variabel & Koefisien & Std. Error & t-statistic & Prob \\
\hline Konstanta & 22.79954 & 1.203314 & 18.94730 & 0.0000 \\
Umur & 0.013312 & 0.026192 & 0.508253 & 0.6125 \\
Pendidikan & -0.170005 & 0.085754 & -1.982472 & 0.0503 \\
Pendapatan & $-2.11 \mathrm{E}-07$ & $2.30 \mathrm{E}-07$ & -0.917278 & 0.3613 \\
Pelayanan & -0.509670 & 0.042583 & -11.96897 & 0.0000 \\
\hline $\mathrm{R}^{2}=0.795912$ & & & \multicolumn{3}{l}{ F hitung $=92.62153$} \\
& & & Sig. F hitung $=0.000000$ \\
\hline
\end{tabular}

Sumber : Data diolah, 2020

Berdasarkan hasil pengolahan data Tabel 7 kolom (coefficients) diperoleh nilai $\mathrm{X}_{1 \mathrm{i}}$ variabel umur sebesar 0,0133 , nilai $\mathrm{X}_{2 \mathrm{i}}$ variabel pendidikan sebesar $-0,1700, \mathrm{X}_{3 \mathrm{i}}$ variabel pendapatan sebesar $-2,1100, \mathrm{X}_{4 \mathrm{i}}$ variabel sistem pelayanan pajak sebesar 0,5096 dan nilai konstanta (C) sebesar 22,7995 maka diperoleh persamaan regresi linier berganda sebagai berikut:

$Y_{i}=22,7995+0,0133 U_{1}-0,1700 \mathrm{TP}_{2}-2,1100 P_{3}-0,5096 \mathrm{SP}_{4}$

Dimana:

$\mathrm{Y}_{\mathrm{i}} \quad=$ Tunggakan $\mathrm{PKB}$

$\mathrm{U}_{1} \quad=$ Umur

$\mathrm{TP}_{2} \quad=$ Tingkat Pendidikan

$\mathrm{P}_{3} \quad=$ Pendapatan Perbulan

$\mathrm{SP}_{4} \quad=$ Sistem Pelayanan 


\section{Uji asumsi klasik}

\section{Uji normalitas}

Keputusan terdistribusi normal tidaknya residual secara sederhana dengan membandingkan nilai Probabilitas JB ( Jarque - Bera) hitungan dengan tingkat alpha 0,05 (5\%). Apabila Prob. JB hitungan lebih besar dari 0,05 maka dapat disimpulkan bahwa residual terdistribusi normal dan sebaliknya, apabila nilainya lebih kecil maka tidak cukup bukti untuk menyatakan bahwa residual terdistribusi normal. Nilai Probabilitas JB hitung sebesar 0,3775 > 0,05 sehingga dapat disimpulkan bahwa residual berdistribusi normal yang artinya asumsi klasik tentang kenormalan dipenuhi.

\section{Uji linieritas}

Berdasarkan hasil perhitungan uji Remsey diperoleh nilai probabiliti sebesar 0,7435pada alpa $5 \%$ atau 0,05 dan nilai probabiliti lebih besar dari $0,05(0,7435>0,05)$. Artinya variabel yang digunakan dalam persamaan regresi linier berganda bersifat linier, sehingga model ini telah memenuhi syarat asumsi klasik dalam analisis regresi.

\section{Uji multikolinearitas}

Berdasarkan hasil perhitungan Inflation Variance Factor (VIF) diperoleh nilai VIF untuk ketiga variabel secara berturut-turut adalah 1.464678, 1.802577, 2.839300dan 2.026588lebih kecil dari 10, maka variabel umur, jam kerja dan jumlah tanggungan bebas dari multikolinearitas. Artinya di dalam model regresi tidak ditemukan korelasi antar variabel independen, sehingga model ini telah memenuhi syarat asumsi klasik dalam analisis regresi.

\section{Uji autokorelasi}

Hasil hasil uji autokorelasi dengan uji Breusch-Godfrey Serial Correlation LM Test didapatkan nilai Prob Chi-Square (2) sebesar 0,4063. Pada saat nilai Prob ChiSquare (2) lebih besar dari tingkat alpha 0,05 (5\%) atau 0,4063>0,05, maka model tidak terjadi autokorelasi, sehingga model ini telah memenuhi syarat asumsi klasik dalam analisis regresi.

\section{Uji heteroskedastisitas}

Berdasarkan hasil perhitungan uji heterokedastisitas dengan Uji Glejser didapatkan dimana nilai $\mathrm{p}$ value yang ditunjukkan dengan nilai Prob. chi square(4) pada $O b s^{*} R$-Squared yaitu sebesar 0,1674. Oleh karena nilai $\mathrm{p}$ value $0,1674>0,05$ maka $_{\mathrm{o}}$ diterima yang berarti model regresi bersifat homoskedastisitas atau dengan kata lain tidak ada masalah asumsi heteroskedastisitas.

\section{Pengujian hipotesis}

\section{Uji F statistik (uji secara bersama-sama)}

Nilai probabilitas (F-statistik) sebesar 0,000000, dimana nilai tersebut lebih besar dari tingkat signifikansi $\alpha=5 \%(0,000000<0,05)$. Ini berarti variabel independen secara bersama-sama berpengaruh terhadap variabel dependen. Artinya, secara bersamasama variabel umur, pendidikan, pendapatan dan pelayanan berpengaruh terhadap variabel tunggakan Pajak Kendaraan Bermotor (PKB) di Kabupaten Tanjung Jabung Barat.

\section{Uji t statistik (uji secara parsial)}


Dapat dijelaskan pengaruh variabel bebas secara parsial terhadap variabel terikat, dalam penelitian ini nilai $\alpha=5 \%$ maka apabila nilai signifikan $<0,05$, maka Ha diterima dan Ho ditolak. Dari analisis tersebut, maka hasil pengolahan data dapat dinyatakan sebagai berikut :

Variabel umur memiliki nilai signifikan sebesar 0,6125 $(>0,05)$ maka secara secara parsial variabel umur tidak signifikan mempengaruhi terhadap tunggakan PKB. Artinya semakin dewasa umur seseorang maka akan sadar untuk membayar pajak sehingga akan menurunkan tunggakan PKB.

Variabel tingkat pendidikan secara parsial tidak signifikan berpengaruh terhadap tunggakan PKB, hal ini dapat dilihat dari nilai signifikan sebesar 0,0503 (>0,05). Tanda yang dihasilkan adalah negatif yang artinya tunggakan PKB akan turun apabila tingkat pendidikan seseorang tinggi.

Variabel pendapatan memiliki nilai signifikan sebesar $0,3613(>0,05)$ maka dapat simpulkan secara parsial variabel pendapatan tidak signifikan mempengaruhi tunggakan PKB. Tanda yang dihasilkan adalah negatif yang artinya tunggakan PKB akan mengalami penurunan apabila pendapatan wajib pajak meningkat.

Variabel sistem pelayanan PKB memiliki nilai signifikan sebesar $0,0000(<0,05)$ artinya secara parsial, variabel pelayanan signifikan berpengaruh terhadap tunggakan $\mathrm{PKB}$, ini dapat dilihat dari nilai signifikan $<0,05$. Tanda yang dihasilkan adalah negatif yang artinya tunggakan PKB akan turun bila sistem pelayanan PKB semakin baik.

\section{Implikasi}

Pada pemilik kendaraan bermotor wajib usianya dewasa dan minimal telah memiliki identitas Kartu Tanda Panduduk (KTP) dan mempunyai pekerjaan tetap atau penghasilan yang cukup untuk membayar pajak khususnya Pajak Kendaraan Bermotor. Oleh karena itu, kepemilikan kendaraan bermotor juga harus memperhatikan aspekaspek tersebut. Begitupula dengan tingkat pendidikan seseorang, yang mana semakin tinggi pendidikan yang ditempuh oleh wajib pajak maka mereka memiliki pengetahuan yang lebih luas tentang pajak dan mereka akan sadar pula untuk membayar pajak khusus Pajak Kendaraan Bermotor.

Pemerintah Daerah wajib mendorong penciptaan lapangan pekerjaan agar pendapatan masyarakat tinggi, bagi pemilik kendaraan khususnya agar memiliki penghasilan tambahan untuk bisa membayar pajak khususnya Pajak Kendaraan Bermotor, sehingga dapat meningkatkan Pendapatan Asli Daerah Kabupaten Tanjung Jabung Barat. Sistem pelayanan yang diberikan akan memiliki dampak terhadap pembayaran pajak kendaraan bermotor. Sistem pelayan yang telah ditempuh oleh Samsat Kuala Tungkal seperti pembayaran secara online yang menyediakan fasilitas mobil keliling akan memudahkan masyarakat dalam pembayaran Pajak Kendaraan Bermotor dan kemudahan akses /jarak yang ditempuh dari rumah atau bisa melakukan pembayaran dirumah sehingga dapat menurunkan tunggakan Pajak Kendaraan Bermotor (PKB) di Kabupaten Tanjung Jabung Barat.

\section{KESIMPULAN DAN SARAN}

\section{Kesimpulan}

Sebagaimana telah diuraikan bahwa penelitian ini bertujuan untuk menguji bagaimana pengaruh umur, tingkat pendidikan, pendapatan dan sistem pelayanan pajak terhadap tunggakan PKB di Kecamatan Tungkal Ilir Kabupaten Tanjung Jabung Barat. Berdasarkan analisis yang dilakukan pada bagian sebelumnya dapat diambil beberapa 
kesimpulan, yaitu:Karakteristik responden dalam hal ini wajib pajak kendaraan bermotor (PKB) orang pribadi di Kecamatan Tungkal Ilir adalah: rata-rata umur responden dalam penelitian ini adalah 33 tahun, rata-rata tingkat pendidikan responden adalah jenjang SMA/sederajat dan rata-rata pendapatan/penghasilan perbulan sebesar Rp 2.486.000.Umur (U)berpengaruh positif dan signifikan terhadap tunggakan Pajak Kendaraan Bermotor, sedangkan tingkat pendidikan (TP), pendapatan (P), dan sistem pelayanan pajak (SP) berpengaruh negatif dan signifikan terhadap tunggakan Pajak Kendaraan Bermotor di Kecamatan Tungkal Ilir, baik secara bersama-sama maupun secara parsial.

\section{Saran}

Berdasarkan dari kesimpulan yang telah dijelaskan, maka dengan ini penulis akan mencoba memberikan saran kepada pihak yang terkait yaitu : diharapkan kepada masyarakat Wajib Pajak mempunyai rasa kesadaran yang tinggi dalam membayar pajak khususnya Pajak Kendaraan Bermotor (PKB).Kantor Samsat perlu mensosialisasikan Peraturan Daerah yang mengatur tentang Pajak Daerah agar dapat mewujudkan masyarakat yang taat Pajak dan menyediakan pembayaran mobil keliling di beberapa pelosok desa sehingga mempermudah akses wajib pajak membayar PKB.

\section{DAFTAR PUSTAKA}

Bohari.(2010). Pengantar hukum perpajakan. PT. Raja Grafindo: Jakarta.

Ghozali, Imam.(2005). Aplikasi analisis multivariate dengan program SPSS. Edisi IV. Badan Penerbit Universitas Diponerogo: Semarang.

Gusfahmi.(2007). Pajak menurut syariah. Rajawali Pers: Jakarta.

Helmi, S; \& Lutfi, M.(2014). Analisa data untuk riset manajemen dan bisnis. USU Press: Medan.

Ikatan Akuntan Indonesia.(2007). Standar akuntansi keuangan Edisi 2007. Salemba Empat: Jakarta.

Mustakim,FR; Hidayat,MS; \& Rahmadi,S. (2016).Analisis penerimaan pajak kendaraan bermotor (PKB) di Provinsi Jambi, Jurnal Paradigma Ekonomika 11 (1)

Nugaheni, Merri.(2010). Faktor-faktor yang mempengaruhi jumlahtunggakan Pajak Kendaraan Bermotor (PKB) pada kantor Dinas Pendapatan Daerah Kota Pekanbaru. Skripsi. Universitas Riau: Riau.

Pahlevi,MR; Hardiani,H; \& Achmad,E. (2019).Analisis efektivitas penerimaan pajak hiburan di Kota Jambi periode 2010-2016, e-Jurnal Perspektif Ekonomi dan Pembangunan Daerah 8 (2), 107-116

Peraturan Pemerintah Republik Indonesia Nomor 65 Tahun 2001 tentang pajak daerah.

Putri, Anita.C.P.(2015). Faktor-faktor yang mempengaruhi wajib pajak orangpribadi di Semarang. Skripsi. Universitas Stikubank: Semarang.

Rosidi, M.(2013). Faktor-faktor yang mempengaruhi jumlah tunggakanpajak kendaraan bermotor pada pada kantor dinas pendapatan daerah tingkat I Pekanbaru Selatan. Skripsi. Universitas Riau: Riau.

Setyawati, Eka.(2013), Faktor-faktor yang mempengaruhi kemauan untuk membayar pajak wajib pajak orang pribadi yang melakukan pekerjaan bebas. Skripsi. Universitas Islam Negeri Syarif Hidayatullah: Jakarta.

Taufik.(2009). Faktor-faktor yang mempengaruhi partisipasi masyarakatdalam membayar pajak kendaraan bermotor di Kabupaten Rokan Hilir. Skripsi. Universitas Riau: Riau. 
Undang - Undang Nomor 28 Tahun 2009 tentang pajak daerah dan retribusi daerah. Undang - Undang Nomor 32 Tahun 2004 tentang pemerintahan daerah.

Waluyo.(2010). Perpajakan Indonesia. Salemba Empat: Jakarta. 